\title{
Science education through experimentation and problem-based learning: "The food and our health"
}

\author{
Folmer, V. ${ }^{1,2}$; Coutinho, R. ${ }^{2}$; Pessano, E.F.C. ${ }^{2}$ Puntel, R. ${ }^{1,2}$; Barbosa, N.B.V. ${ }^{2}$ \\ ${ }^{1}$ PPG Bioquímica, Campus Uruguaiana, Universidade Federal do Pampa; \\ ${ }^{2}$ PPG Educação em Ciências: Química da Vida e Saúde, Centro de Ciências \\ Naturais e Exatas, Universidade Federal de Santa Maria
}

Science education in schools goes through a crisis in their teaching-learning process, due to the fact that their contents are developed out of context, merely bookish, so students have a fragmented and inadequate perception of scientific knowledge. Thus, the aim of this study is to present a proposal for science education developed from experimental activities carried out on short courses for public school students in Uruguaiana-RS. This study is descriptive and was developed from the accompanying of these activities. Courses lasts five days and have problem-based learning as method, students are the center of the teachinglearning process, being the mainly responsible for the development of experimental activities, they use the relationship between food and health as a guiding theme in their research, in order to develop a contextualized and interdisciplinary practice. In the period 2010-2011 were conducted seven courses, attended 185 students. These courses have been characterized by four steps, problematization, experimentation, theorizing, and closing. Students are stimulated to take inventory of their doubts about the topic of the course, and then prepare their own experiments to try to solve the initial questioning. At the end, they must present the experiments and findings to the group. Through these courses were identified that problem-based learning leads to an active involvement of students, providing contact with the scientific method. Moreover, it was observed that the experimental activities become more attractive and challenging the search for knowledge. Therefore, this proposal constitutes an important tool for improving science education in schools.

Key-words: Problem-based Learning, Experimentation, Science Education. Supported by: FAPERGS, CNPq and CAPES. 
This document was created with Win2PDF available at http://www.win2pdf.com. The unregistered version of Win2PDF is for evaluation or non-commercial use only. This page will not be added after purchasing Win2PDF. 